PNL-2616

UC-97a

\title{
Preliminary Study
}

Electromagnetic

Compatibility, Tropospheric and Ionospheric Aspects of SPS MPTS Operations

March 1978

Prepared for

Pacific Northwest Laboratory

Richland, WA 99352

under DOC-DOE Interagency Agreement

EW-78-1-06-1071 
NOTICE

This report was prepared as an account of work sponsored by the United States Government. Neither the United States nor the Department of Energy, nor any of their employees, nor any of their contractors. subcontractors, or their employees, makes any warranty, express or implied, or assumes any legal liability or responsibility for the accuracy, completeness or usefulness of any information, apparatus, product or process disclosed, or represents that its use would not infringe privately owned rights.

The views, opinions and conclusions contained in this report are those of the contractor and do not necessarily represent those of the United States Government or the United States Department of Energy.

\author{
PACIFIC NORTHWEST LABORATORY \\ operated by \\ BATTELLE \\ for the \\ UNITED STATES DEPARTMENT OF ENERGY \\ Under Contract EY-76-C-06-1830
}
Printed in the United States of America
Available trom
National Technical information Service
United States Department of Commerce
5285 Port Royal Road
Springfield. Virginia 22151

Price: Printed Copy 5 _; Microfiche $\$ 33.00$

NTis

- Pages Selling Price

001-025 $\quad 54.50$

$026-050 \quad \$ 5.00$

$051-075 \quad \$ 5.30$

$076-100 \quad \$ 6.00$

$107.125 \quad \$ 6.30$

$126-150 \quad 57.00$

$\begin{array}{ll}151-175 & 57.75\end{array}$

$176-200 \quad \$ 8.50$

$201-225 \quad \rightarrow \quad \$ 8.75$

$226-250 \quad 59.00$

$251-275 \quad 510.00$

$\begin{array}{ll}276-300 & 510.25\end{array}$ 
PNL-2616

$\mathrm{UC}-97 \mathrm{a}$

\author{
Preliminary Study \\ Electromagnetic Compatibility, \\ Tropospheric and Ionospheric Aspects of \\ SPS MPTS Operations
}

\begin{abstract}
Prepared by
U. S. Department of Commerce

Office of Telecommunications

Institute for Telecommunication Sciences

Applied Electromagnetic Science Division

Congested Region Performance Predictions and Model Development Group

Boulder, CO 80302
\end{abstract}

FOR

Pacific Northwest Laboratory

Richland, WA 99352

UNDER

DOC-DoE Interagency Agreement EW-78-I-06-1071 
, 
PNL-2616

\section{TABLE OF CONTENTS}

I. INTRODUCTION. .................. . . . .

II. SPS EMC CONSIDERATIONS. . . . . . . . . . . . . . I II-I

III. POSSIBLE IMPACTS OF THE PROPOSED SPS ON MICROWAVE III-I SPACE-CHANNEL COMMUNICATIONS VIA THE TROPOSPHERIC MED IUS

IV. IONOSPHERIC IMPACT OF THE PROPOSED SPS IV-I

V. CONCLUSION $\quad V-1$

R. REFERENCES R-I 


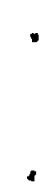




\section{Introduction}

The purpose of this report is to document the results of a preliminary study of the effects of operation of a Solar Power Satellite (SPS) on the general performance of terrestrial and space based electromagnetic systems. In addition, the effects of a passing high energy Microwave Power Transmission System (MPTS) through the troposphere and through the ionosphere are also considered.

This study was undertaken by the Institute for Telecommunication Sciences (ITS) at the request of Battelle, Pacific Northwest Laboratories, Richland, Washington, as out7ined in Interagency Agreement No. EW-78-I-06-1071 between the U. S. Department of Energy and the U. S. Department of Commerce, Office of Telecommunications, Institute for Telecommunication Sciences. In keeping with this agreement, the present report provides comments that should be viewed in conjunction with report "Satellite Power Systems RFI-EMI, Preliminary Draft, AD-02-01/82-029, Initial Assessment, Electromagnetic Compatibility Aspects of Proposed SPS Microwave Power Transmission System (MPTS) Operations," prepared by Batte11e, Pacific Northwest Laboratories, Richland, Washington, December 1977. Recommendations for further investigations that are needed in order to more completely and confidently assess the impact of SPS operation on the performance of all types of electromagnetic systems, is also given in this report.

The SPS as envisioned will be a satellite system in geosynchronous orbit with a solar array of about 144 square kilometers. The purpose of the SPS is to capture solar energy, convert the radiant energy to microwave energy and transmit it to the earth as a beam by means of a phased array antenna one kilometer in diameter at a frequency of $2.45 \mathrm{GHz}$. At the surface of the earth, the energy beam will be captured by an antenna about 100 square kilometers which will convert the microwave energy to high voltage $A C$ power for injection into an electrical power network. It is anticipated that the power available at the earth's surface will be on the order of 4 to 7 gigawatts.

Because of the high amounts of energy that could be beamed to the earth's surface, there is quite a bit of concern about potential biological and atmospheric impact. The biological impact of SPS operation is beyond the scope of this study. The impact of SPS operation on the lower atmosphere, the ionosphere, and on operational telecommunication systems, is addressed in this report in a preliminary manner. Further work must be undertaken in 
in order to answer the major questions concerning the potential hazards to the atmosphere and to telecommunication systems performance caused by MPTS operation. These areas of further work will be described in the subsequent sections of this report. However, for the purpose of emphasis they are listed here:

a. further study on the susceptibility of electronic equipment to SPS emissions (Section II.2);

b. further study on the interference potential of SPS emissions and harmonics to electromagnetic systems (Sections II.3 and II.4);

c. study of the impact of tropospheric attenuation and scattering associated with SPS operation on microwave terrestrial, air/ground and satellite/ground telecommunication systems (Section III.4);

d. further theoretical study on the production of ionospheric irregularities resulting from microwave heating (Section IV.4); and

e. further experimental evidence of the impact of SPS operation on the telecommunication system performance collected in conjunction with a Platteville microwave heating experiment (Section IV.4).

The material described in Section II was provided by Dr. A. D. Spaulding and the material in Section III was provided by Mr. E. Dutton. The material in Section IV was provided by $\mathrm{Mr}$. R. Davis with inputs from Mr. J. Carroli and Dr. M. Ma. Dr. C. M. Rush was responsible for the overall study. 


\section{SPS EMC Considerations}

\section{Introduction}

The RFI/EMC problems associated with the proposed SPS Microwave Power Transmission System as indicated in the material provided by the Pacific Northwest Laboratories of Battelle is basically correct, but a much more detailed investigation will be needed before the actual EMC effects can be determined. It is the purpose of this section to indicate, in some detail-primarily by example--the kinds of EMC questions for which answers will be required.

The EMC "points" raised in the various analyses have been summarized and discussed in Battelle Report AD-02-01/82-029, "Sate11ite Power Systems RFIEMI," Preliminary Draft, December 1977. In this section, only "points" I and II, namely, the effects of incidental energy and spurious emissions from the SPS's are considered. The ionospheric modification effects, potentiai tropospheric effects, and the violation of existing international and national radio regulations will be considered in the next sections. We consider now the points discussed in the above-referenced Battelle report, but with a bit of elaboration.

\section{Susceptibility of Electronic Equipments}

First consider the susceptibility of electronic equipments (non-communicative) to the fields produced at the earth's surface by a single 5 GW SPS. Higher powers and/or additional SPS's, of course, will increase these fields, but in a complex way, dependent on satellite positions, etc. The power density of the earth's surface is given by figure A of the Battelle report. Examples of electronic devices that have a history of EMI susceptibility are heart pacers, anti-lock break devices, other automotive electronic devices, computers, and many, many others. The various RF-radiated susceptibility limit standards are summarized in "A Handbook Series on Electromagnetic Interference and Compatibility, Vol. I," by Donald R. J. White.

First, electro-explosive devices are generally assumed not to survive in fields above $194 \mathrm{~V} / \mathrm{m}\left(100 \mathrm{~W} / \mathrm{m}^{2}\right)$. Power densities of $100 \mathrm{~W} / \mathrm{m}^{2}$ are obtained for the SPS only within approximately $0.006^{\circ}$ of boresight (approximately $7 \mathrm{~km}$ ). 
In the frequency range of interest (1-10 GHz, say), RF-radiated susceptibility 1 imits are given by MIL-STD826, MIL-STD826A, MIL-I-61810, MIL-I-26600, and MIL-I-11748B. The latter is the least restrictive, requiring equipment survival in fields up to $100 \mathrm{~dB}(\mu \mathrm{V} / \mathrm{m})$. The others require survival in higher fields $(135 \mathrm{~dB}(\mu \mathrm{V} / \mathrm{m})$ maximum). A field intensity of $100 \mathrm{~dB}(\mu \mathrm{V} / \mathrm{m})$ corresponds. to a power density of $-46 \mathrm{~dB}\left(\mathrm{~W} / \mathrm{m}^{2}\right)$. Depending on attitude control, etc., (see figure $A$, Battelle report), this power density can be exceeded within $500-1000 \mathrm{~km}$ from boresight. The $135 \mathrm{~dB}(\mu \mathrm{V} / \mathrm{m})$ 1imit corresponds to $-11 \mathrm{~dB}$ $\left(\mathrm{W} / \mathrm{m}^{2}\right)$, which is exceeded only within approximately $15 \mathrm{~km}$ of boresight.

In a report by the Electromagnetic Compatibility Department of Sanders Associates, Inc. (Test Report 1796, June 22, 1972), it is stated that a field of $10 \mathrm{~V} / \mathrm{m}$ (pulsed radar) is border-line for the apparent interference-free operation of computer equipment, but that certain sensitive circuits used in large digital/analog computer systems can be susceptible to levels much lower than this (e.g., acoustical delay lines). A field intensity of $10 \mathrm{~V} / \mathrm{m}$ corresponds to a power density of approximately $-6 \mathrm{~dB}\left(\mathrm{~W} / \mathrm{m}^{2}\right)$.

All of the above is given to indicate that large effects on electronic equipment are at least possible rather far from boresight, especially if more than one SPS is involved. A more detailed investigation than has been performed to date is required in order to accurately assess these effects.

3. Effects of Noise Sidebands on Communication Systems

Figure $B$ of the Battelle report summarizes the noise sideband results and indicates that the power density levels $\left(\mathrm{dB} \mathrm{W} / \mathrm{m}^{2} \mathrm{~Hz}\right)$ will exceed various CCIR recommendations and ITU Regulations concerning line-of-sight microwave links, troposphere scatter, radio astronomy, and deep space research. It is interesting to look a bit closer, however.

The ITU, OTP, FCC define "harmful" interference as being "any emission, radiation, or induction which endangers the functioning of a radionavigation service or of other safety services or seriously degrades, obstructs, or repeatedly interrupts a radio-communication service operating in accordance with regulations." The FCC rules require that anything causing harmful inter- ference to a radionavigation or a safety service to be immediately "turned off." Lesser degrees of interference have sometimes been termed "permissible" . or "negotiable." 
The bands adjacent to the SPS frequency of $2450 \mathrm{MHz}$ are allocated to radio location. Specifically, 2300-2400 is Government radio location, mobile and fixed; $2400-2450 \mathrm{MHz}$ is exclusively radio location, Government allocation, restricted to military use; and 2450-2500 is allocated to fixed, mobile, and radio location (non-government). Government usage in 2450-2500 is also permitted and joint use radar (air defense/air traffic control) can be authorized (2300-2500).

A glance at the Frequency Allocation List, which is a classified document giving military allocations, the Government Master File and the FCC Frequency Master, non-government list, indicates a number of systems (>200) which could potentially receive harmful interference from the SPS noise sidebands. Also, at frequencies further removed from 2450 we have, for example, space-to-earth meteorological satellite links (1690-1710) and broadcasting satellites (2535-2655). Since the SPS's will be in geosynchronous orbit, frequencies that are space-to-earth links are subject to interference since these receiving antennas can be directed more-or-less towards the SPS. (The antennas of other systems such as microwave links and troposcatter links can also be directed toward the SPS, but generally only from the horizon, so that the antenna coupling between the SPS and these should not be as large.)

4. SPS Harmonic Emissions

The Battelle report summarizes the "guesses" as to what the harmonic emission levels might be (figure $C$ ), and points cut that what the harmonic levels actually will be depends critically on the precise details of the SPS design. In any case, the report shows that the $2^{\text {nd }}, 3^{\text {rd }}$, and $4^{\text {th }}$ harmonics will all exceed various CCIR recommendations, and ITU regulations for both Klystron and Amplitron systems. It is assumed that the levels given are mainbeam levels. What is not given in any of the documents is the antenna patterns (or energy density at earth's surface) for the various harmonics. In general, for harmonics, the sidelobes are higher, relative to the harmonic mainbeam, than are the fundamental sidelobes. In order to perform any EMC analysis, these harmonic power densities would need to be known and this can be identified as a subject that requires investigation. We want to take a closer look at each of the harmonics. 


\subsection{Second Harmonic $4900 \mathrm{MHz}$}

This frequency is in the band $4400-4990 \mathrm{MHz}$, which is allocated for Government use only for fixed and mobile services. This band is used heavily by DOD, and the Frequency Allocation List gives approximately 77 different types of systems in the frequency ranges 4400-4990,4400-5000,4400-5250,4400-5400, . 4450-4950, 4500-4950, 4600-5000, 4890-4990, 4900-5100, and 4900-5300. These systems cover a large range of uses--radio sets, radio relay, radar data relay, . telemetry, video data link, troposcatter links, TV transmission, etc.

\subsection{Third Harmonic $7350 \mathrm{MHz}$}

This harmonic is in the band 7300-7450 which is allocated for Government use for fixed-satellite (space-to-earth), fixed, and mobile. As will be seen, this harmonic probably has the greatest potential of any of the harmonics for causing concern.

The SPS's are to be in geosynchronous orbit and the increasing number of satellites in orbit has already resulted in potential "parking" problems, especially in certain preferred sectors of the orbit. New uses for communications satellites, including domestic services, TV distribution, and mobile services, are rapidly emerging. Also, new users, in addition to current users such as NASA, INTELSAT, and the military are eager to occupy orbit slots, SPS being one such new user. Thus, it is reasonable to expect that there will be communication satellites "close" to the SPS, so that the downlink frequencies are subject to interference from SPS. Note that $7350 \mathrm{MHz}$ is in the center of one of the Government down 7 ink bands. There are currently approximately seven geostationary communication satellites using the 7-8 $\mathrm{GHz}$ band plus probabiy a fair number of other military satellites (geostationary and orbiting) using this band. Figure 2.1 shows earth station locations for the 4-6 GHz band. There is no such complete figure for the 7-8 GHz band, but considering all the military bases, the mobile satellite terminals, the airborne terminals (e.g., airborne command post), etc., such a figure for 7-8 GHz would look equally crowded.

We next look at another use of the 7300-7450 band, namely, microwave relay links. There are many military microwave links with which $7350 \mathrm{MHz}$ might interfere, but, as an additional example, we will look at the FAA RML-4 links. Figure 2.2 shows the FAA microwave relay system. These links 
relay all the radar information from the remote radars to the air traffic controllers for all in-route air traffic control. The RMS-4 links are divided into low-band and high-band frequency groups. The low-band groups use 7125 to $7650 \mathrm{MHz}$. Each link has six channels, four from radar to ATC operator and two from ATC to radar. The frequency 7350 falls either in channel 2 or 3 (the low-band group is further sub-divided), and these channels contain all the radar information--beacon video, normal video, and MTI video. While the third harmonic, 7350, may not interfere, perhaps the main problem would be to convince the FAA of this. The RML-4 is an example of a safety service system which the regulations concerning harmful interference are designed to cover.

\subsection{Fourth Harmonic $9800 \mathrm{MHz}$}

The frequency $9800 \mathrm{MHz}$ is in the band 9500-10000, which is allocated to radio location, both Government and non-government use but primarily for Government use. Also, in this band all Government, non-military radio location shall be secondary to the military services. Again, the Frequency Allocation List gives a large number (approximately 26) of system types that use the frequency $9800 \mathrm{MHz}$.

\section{Conclusion}

The above short discussion is certainly not meant to be all inclusive, but gives examples to show that the EMC questions related to SPS operation require further study. We see that many of the frequencies that could be subject to interference are Government frequencies, which generally means that EMC problems can have various non-technical aspects--such as DOD and "national defense," the FAA and "air traffic safety," etc. Thus, in addition to more detailed investigations--examples of which are given above--the political problems that could arise as the result of SPS-generated interference must be addressed by the owner/operator of the SPS. These "political" problems may be more difficult to solve than the technical issues. 


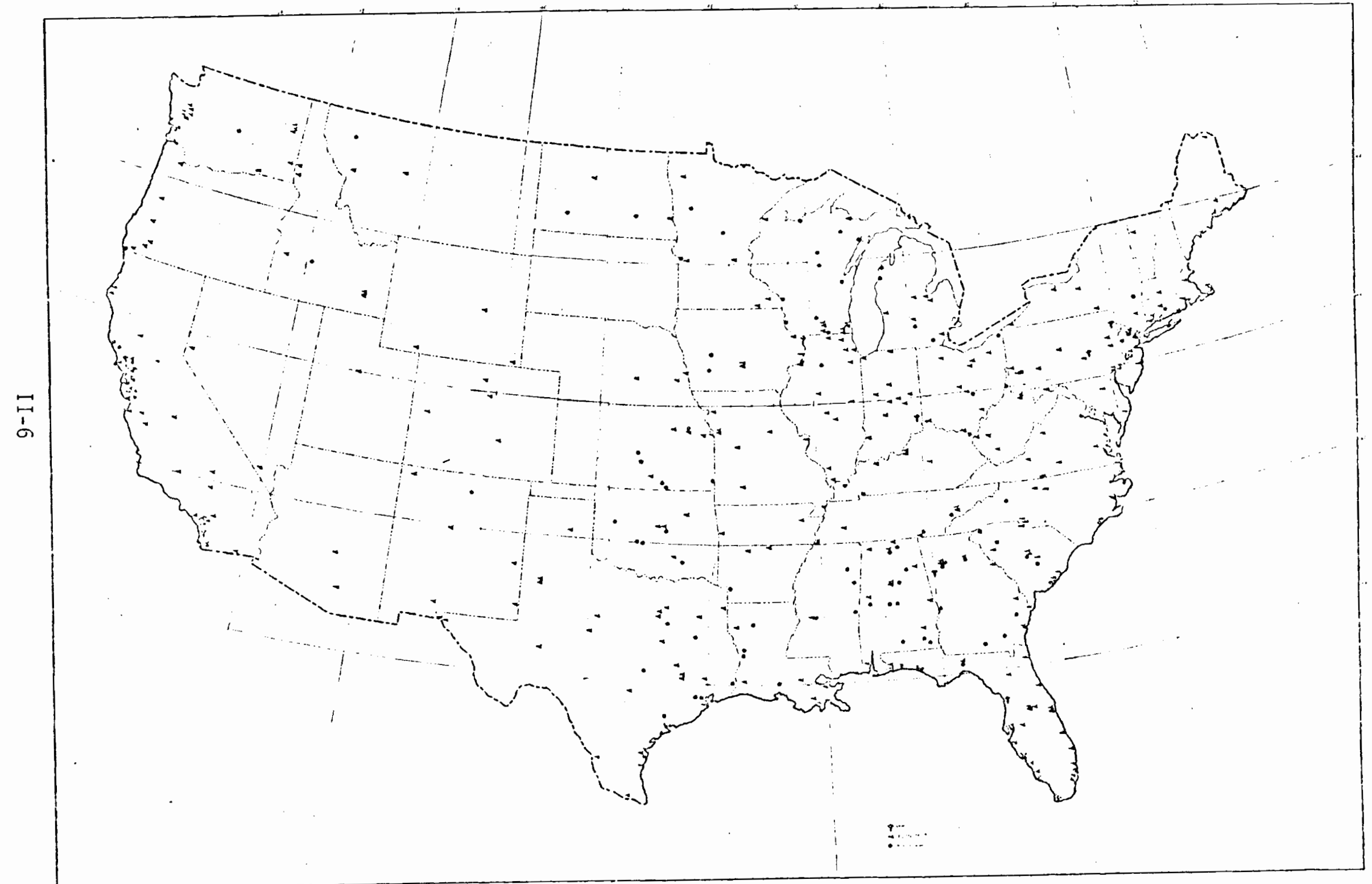

Figure 2.1. 4-6 GHz Satellite Terminals. 


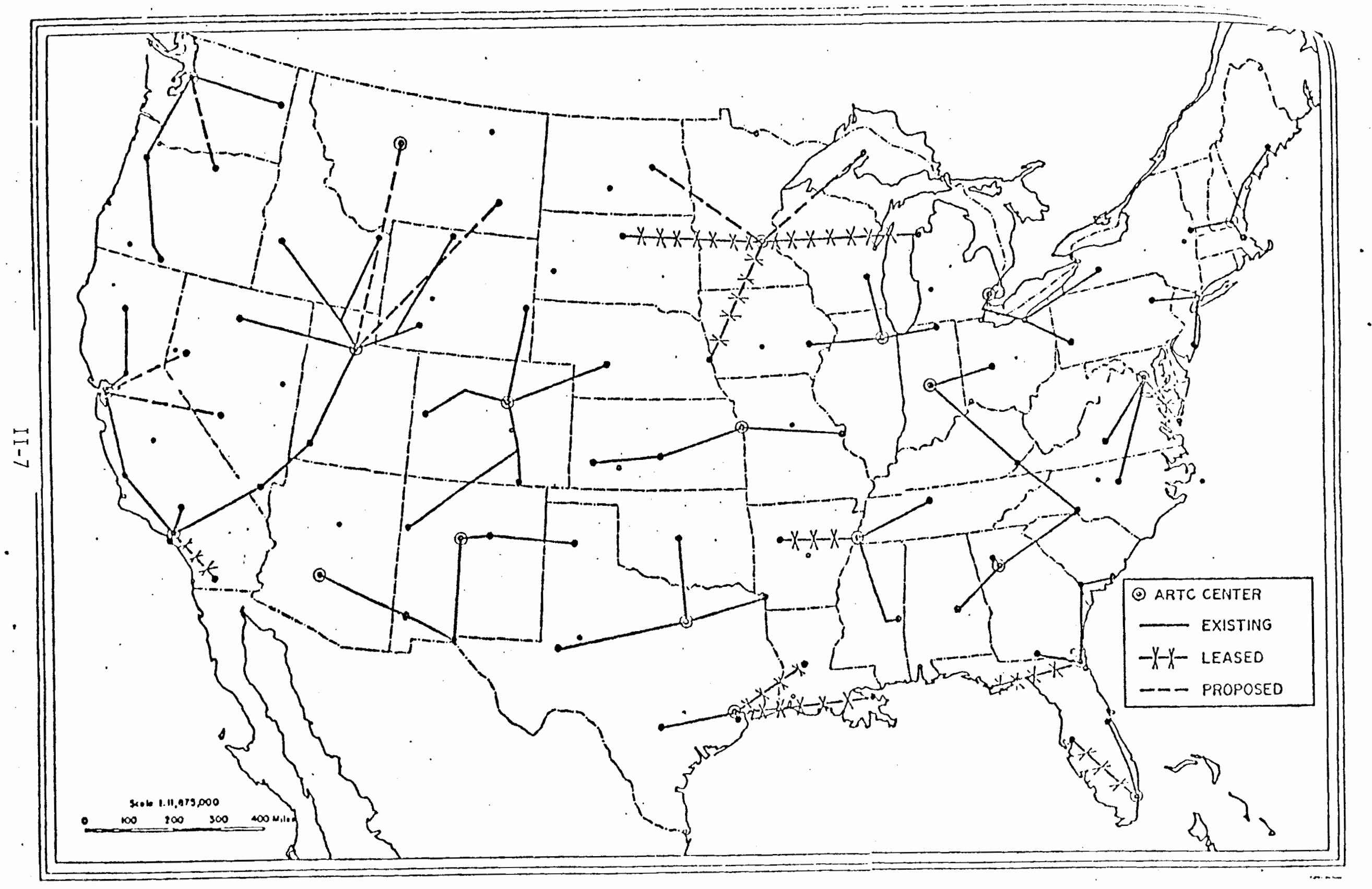

Figure 2.2. FAA Microwave Relay System. 


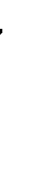

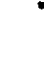




\section{Possible Impacts of the Proposed SPS on Microwave Space-Channel Communications Via the Tropospheric Medium}

\section{Introduction}

The choice of an operating frequency is $2.45 \mathrm{GHz}$ for the $\mathrm{C} N$ signal beamed down from the Solar Power Satellite (SPS). This frequency has been judiciously selected in an attempt to avoid the ionospheric effects common to lower frequencies and the tropospheric effects associated with higher frequencies (i.e., a transmission "window" frequency). However, neither one of these effects is totally avoidable, although it is generally conceded that ionospheric effects will be more important than tropospheric effects. The tropospheric effects, however, especially with the high-power transmission proposed for the MPTS operation, cannot be totally ignored.

2. Attenuation by the Troposphere

It is to be expected on theoretical grounds that at a frequency of 2.45 $\mathrm{GHz}$, radio waves suffer little attenuation by the lower atmosphere of the earth. Gaseous absorption, due to both oxygen and water vapor absorption, is expected to contribute no more than about $1 \mathrm{~dB}$ (Bean and Dutton, 1968), and rain absorption no more than another $2 \mathrm{~dB}$. This total of $3 \mathrm{~dB}$, although small, represents a loss of 50 percent of the originally transmitted power. This is, to be sure, a worst case situation. On the average, one would expect about $0.2 \mathrm{~dB}$ of attenuation at a frequency of $2.45 \mathrm{GHz}$ on a $30^{\circ}$ elevation angle path to a satellite in a temperate climate characterized by a gaseous atmosphere with no rain (Bean and Dutton, 1968). Even this, however, represents a 4.5 percent loss of power. Clearly, annual variations in climate and temperature represent potential losses of several tens of millions of watt-years of energy during years of large excursions from mean conditions.

\section{Particulate Scatter in the Troposphere}

The potential system-related problems associated with tropospheric attenuation are not the only problems that could result from the impact of the troposphere on the SPS. Particulate scatter at the proposed operating frequency of $2.45 \mathrm{GHz}$ is likely to affect microwave communications systems operating in the troposphere. 
Consider first, precipitation. When we talk percentages, the numbers appear sma11, especially when discussing raindrop scatter, but it must always be remembered that what's smal1 to one system (specifically the SPS) could represent a blackout to a smaller powered communications system. Furthermore, if we consider effects at microwave frequencies harmonic to $2.45 \mathrm{GHz}$, these percentages become higher. This implies potentially deleterious effects, even though the harmonic power levels transmitted are at reduced values.

It is well-known (Kerr, 1951) that an assumed spherical precipitation particle will scatter energy at $2.45 \mathrm{GHz}$ in the pattern of an elementary dipole. If $\theta$ is the angle off the forward direction (i.e., the scattering angle), the directivity $D_{\theta}$, is given by (Blake, 1966), with $D_{\pi}$ the backscatter directivity,

$$
D_{\theta}=D_{\pi} \cos ^{2} \theta
$$

If we now consider the bistatic radar equation (Dutton and Dougherty, 1973) to be written as (ignoring atmospheric attenuation effects)

$$
\begin{aligned}
\vec{P}_{r} & =\rho_{i}\left[\frac{\sigma(\lambda)}{\bar{l}_{\pi} L_{r}^{2}}\right]\left[\frac{\lambda^{2} g_{r}}{4_{\pi}}\right], \\
\sigma(\lambda) & =\int_{v} \eta(\lambda) d V \approx \bar{n}(\lambda) v, \\
V & \approx \frac{\pi}{4}\left(\delta_{r} L_{r}\right)^{2} \operatorname{dcsc} \theta, \delta_{r} L_{r}<d
\end{aligned}
$$

In (2), (3), and (4)

$V \quad$ is the common volume intersection of the SPS main beam and the main beam of a co-channel microwave communications system (MWS) receiver on the earth's surface--assumed a complete intersection of the two beams and completely filled by particles, herein, $d \quad$ is the diameter of the SPS main beam at $V$, assumed $\approx 10 \mathrm{~km}$, $\delta_{r}$ is the beamwidth of the MWS mainbeam, $n(\lambda)$ is some average "reflectivity" (Battan, 1959) of the particles in V,.. 
$\sigma(\lambda)$ is the scattering cross-section of $V$,

$\lambda \quad$ is the wavelength of the SPS $(\sim 12.24 \mathrm{~cm})$, and of the MWS carrier,

$L_{r}$ is the distance from the MWS to $V$,

$\bar{P}_{r}$ is the average power scattered to the MWS antenna,

$g_{r}$ is the main-beam gain of the MWS antenna,

and

$\rho_{i} \quad$ is the power density incident at $V$, assumed herein $=20 \mathrm{mw} / \mathrm{cm}^{2}$ or $20 \times 10^{7} \mathrm{w} / \mathrm{km}^{2}$.

We can further write, at $2.45 \mathrm{GHz}$

$$
\bar{n}(\lambda)=\frac{\pi^{5}}{\lambda_{\mathrm{cm}}^{4}}|k|^{2} Z \cos ^{2} \theta \times 10^{-7} \mathrm{~km}^{-1}
$$

by using the Rayleigh-region backscatter reflectivity formulation (Bean et al., 1970) and (1), assuming the angle of scatter, $\theta$, is the constant for al 1 particles in $V$ that scatter into the MWS mainbeam. In (5)

$$
|k|^{2} \approx 0.93 \text {, for rain, }
$$

and $Z$ is the so-called "radar reflectivity factor."

For a rain rate, $R$,

$$
Z \approx 200 \mathrm{R}^{1 \cdot 6} \text {, }
$$

a formulation that has been we1l-verified experimentally (Battan, 1959; Hubbard et a 1., 1973). In (5) and (6), $Z$ is in $\mathrm{mm}^{6} / \mathrm{m}^{3}$ and $R$ is in $\mathrm{mm} / \mathrm{hr}$.

Suppose we now consider scatter at $\theta=45^{\circ}$, and let us choose other (presumably reasonable) values; namely

$$
\begin{aligned}
& g_{r}=10^{4}(40 \mathrm{~dB}), \text { and } \\
& \delta_{r}=0.025 \mathrm{radian}\left(\sim 1.5^{\circ}\right), \\
& L_{r}=5 \mathrm{~km}
\end{aligned}
$$

and a moderate

$$
R=10 \mathrm{~mm} / \mathrm{hr} \text {. }
$$


Then, using (2) through (6), we obtain

$$
\bar{P}_{r}=6.65 \times 10^{-6} w \text { or }-51.8 \mathrm{dBw} \text {. }
$$

If we now consider the impact of melting hail on the same MWS, Battan (1971) indicates that the average reflectivity can be written as

$$
\bar{n}(\lambda)=2.84 \times 10^{-11} \frac{\mathrm{Z} e}{\lambda_{\mathrm{cm}}^{4}} \cos ^{2} \theta \mathrm{km}^{-1}
$$

with a

$$
\mathrm{z}_{\mathrm{e}} \approx 5 \times 10^{6} \frac{\mathrm{mm}^{6}}{\mathrm{~m}^{3}}
$$

roughly appropriate at $2.45 \mathrm{GHz}$. Whence,

$$
\bar{P}_{r}=4.17 \times 10^{-9} w \text { or }-83.8 \mathrm{dBw} \text {. }
$$

This figure is smaller than that of (7) because although hail sizes are generally much larger than raindrops, the number density of them per unit volume is considerably less than for rain (Douglas, 1964). In any case, both (7) and (9) are values well in excess of ITU requirements for maximum permissible unwanted signal level at $2.45 \mathrm{GHz}$ (ITU, 1976). These values run more on the order of $-140 \mathrm{dBw}$. Of course, atmospheric attenuation may reduce the values of (7) and (9) some when it is accounted for in (2), but not nearly enough.

There is considerable variability in space and time of received unwanted signals reflected from storms. This variability depends upon numerous climatic and meteorological variables (Zuffery, 1972; Dutton, 1977), and should be assessed individually for the particular system configuration of concern.

Atmospheric particulate matter other than precipitation could have some degree of impact in regions of highly concentrated particle population. Such concentrations could be generated by the launch vehicles associated with the building and maintenance of the SPS. However, Fraser (1959) indicates a large .. particle concentration is about $2500 / \mathrm{cm}^{3}$, and that average particle size is about $10^{-5} \mathrm{~cm}$. If this is the case, then the impact would be for less than that for moderate rain, since $z \propto\left(10^{-5}\right)^{6}$. 
A possible exception exists in the case of sandstorms, however, because sand particle sizes are nearly the same as raindrops (Gary et a1., 1972). As an example, we can calculate equation (2) for a sandstone of $0.1 \mathrm{~cm}$ radius and a particle concentration the same as for rain. $|K|^{2} \cong 0.2$ for sand, and if and if we again use $\theta=45^{\circ}$, about $-58.4 \mathrm{dBw}$ would result at the MWS, again, for a fully-filled common volume. It should be noted, however, that the whole area of non-water particulate scatter at microwave frequencies has not been extensively investigated.

Significant deviation can be expected for frequencies harmonic to 2.45 $\mathrm{GHz}$. This is because (2) is valid only at $2.45 \mathrm{GHz}$, having been evaluated from an expression that varies as $f^{4}$, for frequency, $f$. The deviations from the form of (2) begin to occur for $f>10 \mathrm{GHz}$, in the case of rain.

4. Recommended Studies

It is recommended that the aforementioned problems, attenuation and scattering and their variability from location to location, be investigated in order to isolate the areas of potentially greatest impact on microwave terrestrial, air/ground, and satellite/ground links. After the areas posing the greatest potential hazard are determined, detailed examination of their variability would be desirable. This should be done by theoretical and numerical means for cost-effective considerations. It seems prudent to first estimate the potentially largest areas of concern by theoretical and possibly computer simulation studies, and then attempt experimental verification of those areas. 


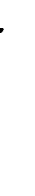


IV. Ionospheric Impact of the Proposed SPS

1. Introduction

Because of the high amounts of power that will be associated with the MPTS, it is generally conceded that the power beam will create changes and disturbance to the structure of the ionosphere as it passes through that portion of the terrestrial environment. In this section, we briefly review the work done to date to evaluate the severity of the disturbance thus created and to estimate the impact of the disturbance on the performance of electromagnetic propagation systems that use the ionosphere as a medium of transmission. The material contained herein is drawn heavily from the report, "Space-Based Solar Power Conversion and Delivery Systems-Study, Vol. III," Raytheon Corporation, 1977. In this section, further reference to this report wi17 be given as Raytheon, 1977. In addition, the contents of Raytheon, 1977, at least as far as the ionospheric impact is concerned, has been recently summarized by Holway et al. (1978).

2. Microwave Effects on Ionospheric Structure

At microwave frequencies, the equation for the index of refraction can be written as

$$
\mu=1-\frac{q^{2}}{2 \varepsilon_{0} m}\left(\frac{n}{\omega^{2}}\right)
$$

where

$$
\begin{aligned}
\mu & =\text { refractive index } \\
q & =\text { charge of the electron } \\
\varepsilon_{0} & =\text { permittivity of free space } \\
m & =\text { mass of the electron } \\
n & =\text { electron density } \\
\text { and } \omega & =\text { frequency of the radio wave. }
\end{aligned}
$$

It is readily apparent that the amount of refraction is greatest where the electron density is the greatest. In the ionosphere, this occurs at the peak of the $F 2$ region at heights between $250-450 \mathrm{~km}$ depending on local time, season, solar activity and geographic (geomagnetic) location. 
The equation for the absorption coefficient a at microwave frequencies can be written as:

$$
\alpha=\frac{q^{2}}{2 \varepsilon_{0} m c}\left[\frac{n\left(v_{e n}+v_{e j}\right)}{\omega^{2}}\right]
$$

where

$$
c=\text { velocity of light }
$$

$v_{\text {en }}=$ the collision frequency between electrons and neutral particles

$v_{e i}=$ the collision frequency between electrons and ions.

It is to be expected that the heights at which absorption will be most important will occur around $70 \mathrm{~km}$ and near the F-region peak.

The rate of attenuation of the wave is $e^{-\beta x}$, where $\beta=2 \alpha$ and $x$ is distance traveled. Since (2) has $\omega^{2}$ in the denominator, the microwave beam ( $f=2.45 \mathrm{GHz}$ ) suffers very little attenuation in passing through the ionosphere. Even though the heating effect of the beam increases the attenuation by an order of magnitude, absorption of the microwave energy by the ionosphere is insignificant.

The power dissipation of an electromagnetic wave can be expressed as

$$
Q=2 \alpha\langle S\rangle=\frac{e^{2}}{\varepsilon_{0} m c}\left(\frac{n v}{\omega^{2}}\right)\langle S\rangle
$$

where $S$ is the Poynting vector and the brackets indicate averaging over an rf cycle. According to (3) ohmic heating by a power beam is proportional to $S / f^{2}$. Thus, by using a much lower frequency than the proposed microwave frequency, it should be possible to duplicate the microwave heating with a very much lower power density. Because of this dependence of heating on frequency, information gained from heating experiments at Platteville (Utlaut, 1975) and Arecibo (Gordon and Carlson, 1974) to infer some of the effects of the microwave beam can be used.

There are basic differences, however, between the HF heating effects and those we can expect at microwaves. At HF, where the wave frequency is comparable to the plasma frequency, the wave suffers additional refraction, focusing, and deviative absorption. Airy "swelling" amplifies the power beam near the HF reflection height, so that it is increased by an order of magnitude over a height range of $1-2 \mathrm{~km}$. In contrast to this narrow range 
of HF heating, the microwave power beam is a constant heat source over tens of $\mathrm{km}$. In addition, the HF interaction area with the ionosphere has a diameter of about $100 \mathrm{~km}$ in the F-region, while the microwave beam will be $10 \mathrm{~km}$ or less in diameter.

The HF experiments triggered instabilities, caused enhanced airglow at $6300 \mathrm{~A}$, and produced field-aligned structures capable of scattering radiation at VHF and UHF. These results are most succinctly organized in the special Issue of Radio Science (1974). Not all of these effects will occur at microwave frequencies. However, it seems reasonable to expect that a power flux of $20 \mathrm{~mW} / \mathrm{cm}^{2}$ will produce ionospheric effects similar to those that appeared in the HF modification experiments. Other effects, presently unpredicted, may also occur.

\subsection{F-layer Heating}

Ohmic heating in the ionosphere causes a rapid increase in electron temperature $\mathrm{T}_{\mathrm{e}}$ and a much slower decrease in electron density.

The amount of temperature increase depends on the power density. According to the results of Meltz and LeLevier (1970), after $50 \mathrm{sec}$ of heating, the increase is about $700^{\circ} \mathrm{K}$ for a $20 \mathrm{~mW} / \mathrm{cm}^{2}$ beam, $1200^{\circ} \mathrm{K}$ for a 80 $\mathrm{mW} / \mathrm{cm}^{2}$ beam, and $1900^{\circ} \mathrm{K}$ for a $320 \mathrm{~mW} / \mathrm{cm}^{2}$ beam (see figure 4.1 ). The high temperatures occur only in a slab $10 \mathrm{~km}$ thick parallel to the meridian plane containing the axis of the power beam.

The most important cooling mechanism in the F-region is thermal conduction by the electrons along magnetic field lines. The amount of heat from a microwave power beam is so large that most of it must be conducted to altitudes near $200 \mathrm{~km}$, where enough collisions with neutral particles take place to cool the electrons. Temperatures are higher at night because fewer electrons are available to conduct heat away from the dissipation region.

Calculations of F-region heating, in terms of normalized dissipation Q/nv, are tabulated for three power densities corresponding to systems that would have total power outputs of 5, 10, and $20 \mathrm{GW}$ (Raytheon, 1977). The amount of heat deposited depends on the length of the magnetic field line heated by the power beam, which is $D / \sin \alpha$, where $D$ is the diameter of the beam, and $\alpha$ is the angle that the beam makes with the magnetic field line. 
When the microwave beam is turned on, calculations described in Raytheon, 1977 show that electron temperatures increase rapidly and reach a steady-state value about twice their undisturbed value in about $30 \mathrm{sec}$. Electron densities reach a steady state 45 percent below ambient after about $2000 \mathrm{sec}$. Electrodynamic drift causes the electron density to decrease to about 8 percent below ambient in $200 \mathrm{sec}$; it then returns to ambient in the same length of time after the beam is turned off.

The nighttime variation of $T_{e}$ with altitude is shown in figure 4.2 for three power densities at two sites, one located in the Northeast and the other in the Southwest part of the United States. Figure 4.3 shows fractional increases of $T_{e}$ in the meridian plane in the form of contours. The largest increase at the Northeast site for $20 \mathrm{~mW} / \mathrm{cm}^{2}$ density is 50 percent in the vicinity of the F-region peak. Increases of 25 percent occur at heights hundreds of $\mathrm{km}$ above the beam. Daytime temperatures during heating are higher than nighttime, but the increase over ambient is smaller than at night because the higher daytime conductivity removes heat faster. Fractional decreases in electron density at the F-region peak are greater at night than in daytime.

\subsection{D-region Heating}

Because of the high collision frequency in the D-region, electron temperature reaches a steady state in milliseconds.

D-region temperature is shown in figure 4.4 plotted as a function of incident power flux for three heights, 60,100 , and $110 \mathrm{~km}$. Te is lower at 100 and $110 \mathrm{~km}$ than at $60 \mathrm{~km}$. This is due to the fine structure transitions in atomic oxygen. The same factor causes the decrease of $\mathrm{T}_{e}$ above $90 \mathrm{~km}$ in a plot of $T_{e}$ against altitude.

Electron density in the D-region is a complicated function of chemical reactions, but it may be expected to respond to the jump in temperature when the power beam is turned on. To a first approximation the electron density is described by the recombination equation

$$
\frac{\partial n}{\partial t}=P-\alpha\left(T_{e}\right) n^{2}
$$

where $P$ is the production rate due to photo-ionization. In the absence of the power beam 


$$
P=\alpha\left(T_{0}\right) n^{2}
$$

where $T_{0}$ is the equilibrium temperature.

If the dissociative recombination coefficient is taken as

$$
\alpha=5 \times 10^{-6}\left(180 / T_{e}\right)
$$

it can be shown (Raytheon, 1977) that the electron density increases over periods of the order of ten minutes.

Calculations given in Raytheon, 1977 yield results as shown in figure 4.5. D-region electron density is plotted against time in the first $1000 \mathrm{sec}$ after microwave power turn-on. The density increases at 70 and $80 \mathrm{~km} \mathrm{height,}$ especially during the first $500 \mathrm{sec}$. At $60 \mathrm{~km}$ little change takes place in $\mathrm{n}$.

The calculated D-region absorption coefficient is shown in figure 4.6 plotted against height for a 10-MHz ordinary wave under three conditions: no heating, after $1 \mathrm{sec}$ of heating, after $20 \mathrm{~min}$ of heating. Very high absorption is indicated between 80 and $100 \mathrm{~km}$ after $20 \mathrm{~min}$ of heating. Two further features of D-region interaction with a power beam should be mentioned. The first is a decrease in absorption below $70 \mathrm{~km}$ when the beam is turned on.

Secondly, the horizontal winds that move fluid across the power beam create a wake outside the beam in the case of electron density. In the case of temperature with its short relaxation time, the disturbance is confined to the power beam.

3. Evaluation of Impact on Systems

The following discussion of the probable impact of the MPTS on other users of the ionosphere is based on two assumptions. The first is that ionospheric changes due to the microwave power beam will be of the same general kind as the natural changes that have been observed in the ionosphere. The second is that knowledge gained from the HF heating experiments will give some guidance as to the kind of effects to be expected from microwave heating. 
A specific example of these assumptions would be that under microwave heating, we may expect the formation of irregularities, which will affect users of the ionosphere much as naturally occurring irregularities in polar and equatorial regions have affected users. This is substantiated by the fact that such irregularities have been observed as a consequence of heating at HF. Some of the ionospheric abnormalities that may arise under heating, and their probable effect on certain types of systems, are as follows. (The types. of systems considered are navigation systems, communications systems, and DoD radars.)

Absorption--This may cause HF signal loss and modify VLF navigation signals. Questions to be studied relate to the geographical extent and magnitude of the absorption, and its location relative to the MPTS disturbance. Ionospheric Depletion--Gradients caused by the power beam will tend to limit the useful HF range and displace the power beam itself. What is the geographical size and intensity of the effect? What is the effect of continuous heating?

Ionospheric Irregularities--This would cause scattering of radio energy propagated through the disturbed region. Questions of interest are whether non-linear effects are involved, whether the effect is a function of the power density of the beam, what the lifetime and geographical extent of the scattering are. All types of systems, operating at frequencies, up to SHF could be affected by this type of disturbance.

Traveling Waves--Scattering of energy and variations in radar target location are possible effects. The existence and severity of the effect should be investigated. All systems could be affected.

RFI Harmonic Generation--This would cause interference to all other users. Would it occur?

Chemistry Changes--The effect of this is unknown.

In the absence of experimental data on the effects of microwave heating on radio systems, Raytheon, 1977, cites three examples that may be representative of such interaction. The first is the effect of a magnetic storm on $16 \mathrm{kHz}$ propagation over a $1500 \mathrm{~km}$ path. A phase advance of 2 cycles takes place, corresponding to a change in phase path of $37.5 \mathrm{~km}$. This would be a. serious error in a navigation system. 
The evidence of irregularities on the LES- 6 satellite signal at $254 \mathrm{MHz}$ is the second example. Scintillation gives rise to fading of the order of $25 \mathrm{~dB}$.

The third example is the effect of the Platteville HF heater on Doppler and backscatter records. With the heater off, the Doppler record is a simple spectrum and the backscatter record has a return confined in range and azimuth. Sixteen sec after turn-on, the Doppler shift shows a wider range of frequencies, and multiple returns in range and azimuth are seen in the backscatter record. After $30 \mathrm{sec}$ the evidence of disturbance is more prominent on both records.

In the following table taken from Raytheon, 1977, a number of current systems are listed with the type of degradation expected from the MPTS and recommended experiments needed to study the interaction.

\begin{tabular}{|c|c|c|}
\hline System & Effect & Experiment \\
\hline OMEGA $(10.2 \mathrm{kHz})$ & Sudden phase anomaly & $\begin{array}{l}\text { Compare theory with } \\
\text { observed SPA's }\end{array}$ \\
\hline LORAN C $(100 \mathrm{kHz})$ & $\begin{array}{l}\text { No groundwave effects } \\
\text { expected; possible } \\
\text { skywave }\end{array}$ & $\begin{array}{l}\text { Run LORAN } C \text { in parallel } \\
\text { with OMEGA }\end{array}$ \\
\hline $\begin{array}{r}\text { NAVSTAR }(1200 \mathrm{MHz}, \\
1600 \mathrm{MHz})\end{array}$ & $\begin{array}{l}\text { Two-frequency users } \\
\text { not affected; damage } \\
\text { to single frequency } \\
\text { users }\end{array}$ & $\begin{array}{l}\text { Observe effects of power } \\
\text { beam; monitor performance } \\
\text { of GPS }\end{array}$ \\
\hline HF communications & Propagation outages & $\begin{array}{l}\text { Operate several links } \\
\text { near heating region }\end{array}$ \\
\hline AFSATCOM $(260,360 \mathrm{MHz})$ & $\begin{array}{l}\text { Fading and multipath } \\
\text { signal degr }\end{array}$ & $\begin{array}{l}\text { Simulate with ground- } \\
\text { based system; measure } \\
\text { scintillations at } \\
400 \mathrm{MHz}\end{array}$ \\
\hline $\begin{array}{l}\text { INTELSAT/MARISAT } \\
\quad(1200,1600 \mathrm{MHz})\end{array}$ & Severe fading & $\begin{array}{l}\text { Measure scintillations } \\
\text { during heating }\end{array}$ \\
\hline DoD radars & $\begin{array}{l}\text { Masking of targets due } \\
\text { to aspect-sensitive } \\
\text { scatter from irregu- } \\
\text { larities, Doppler } \\
\text { spreading }\end{array}$ & $\begin{array}{l}\text { Operate small-scale } \\
\text { radar during heating }\end{array}$ \\
\hline $\begin{array}{l}\text { Surveillance and } \\
\text { SPACEPAK radars }\end{array}$ & $\begin{array}{l}\text { Severe target fading } \\
\text { in main lobe; range } \\
\text { errors }\end{array}$ & $\begin{array}{l}\text { Ground-based backscatter } \\
\text { during heating }\end{array}$ \\
\hline
\end{tabular}




\section{Recommendations for Further Work}

The basic recommendations for further efforts 7 isted in Raytheon, 1977 reflect a high degree of expertise and understanding of the necessary technology that must be addressed in order to demonstrate the feasibility of SPS operation.

In spite of the many theoretical studies generated by the HF heating experiment, only a small effort has been devoted to date to studies of the instabilities that may be produced by microwave transmissions. This appears to be changing somewhat however--witness the work of Perkins and Roble (1978) about to be published. Instabilities that should be examined thoroughly are the drift-resistive instability (driven by large plasma gradients), fieldaligned diffusion modes and self-focusing instabilities, and enhanced airglow in the heated F-region.

Several areas where further theoretical studies can be undertaken are spelled out in Raytheon, 1977:

1. inclusion of electrodynamic drifts in F-region theory and wind drifts in D-region theory,

2. inclusion of loss due to vibrational excitation of $\mathrm{N}_{2}$ in F-region theory,

3. leaking of particles to adjacent field lines may be important in microwave disturbance, which is hotter and more limited in extent than HF disturbance,

4. conductivity changes in the D-layer and its effect on dynamo currents,

5. effects of chemical recombination and photo production in the F-region, as part of a better model of ionospheric chemistry.

These studies are needed in order to develop the theoretical models of the ionosphere and changes to the ionosphere needed to properly assess the impact of SPS operation.

It is necessary also to have access to data taken under controlled experimental conditions that simulate the effects of SPS operation on telecommunication system performance. In this regard, the Platteville and Arecibo modification experiments are useful but as mentioned earlier, they were conducted at frequencies near the ionospheric plasma frequency. Thus, the induced ionospheric changes that accompanied these experiments can be extrapolated to other frequencies in a very limited manner. It is for this reason in fact that proposals have been made to duplicate MPTS effects using frequencies in the 15 to $30 \mathrm{MHz}$ range. Specifically, the proposals to modify and 
use the Arecibo facility [Perkins and Roble (1978), Duncan and Gordon (1977)] and to build a heater facility in the Southwest U. S. (Raytheon, 1977) are addressed to this topic. There are advantages to both proposals. Use of a modified Arecibo facility would no doubt result in a vastly improved understanding of high frequency-generated ionospheric instabilities that could easily be extrapolated to the frequency of the SPS $(2.45 \mathrm{GHz})$. A totally new facility located in the Southwest U. S., such as described in Raytheon, 1977, would present a capability to very accurately simulate high-powered microwave effects in the ionosphere.

It should be pointed out, however, that there are certain disadvantages to both proposals. Because of obvious logistic problems, the location of and types of ancillary telecommunications experiments needed to ascertain the effects of SPS operation on the performance of radio systems, would be 1 imited in the Arecibo heating experiment. Building a new heating facility in the Southwest U. S., on the other hand, nearly duplicates, in principle, a capability that currently exists in the same portion of the country--namely, the Platteville heating facility operated by the Institute for Telecommunication Sciences.

Below is 1 isted a rough estimate of the cost to provide a $2 \mathrm{MW} \mathrm{CW}$ input, $25 \mathrm{MHz}$ capability at Prattevilie:

Proposed Antenna: Constructed similar to existing 5-10 MHz heating array, scaled to $25 \mathrm{MHz}$ without broadband capability.

Grade Construction Site

Install Ground Screen

Build Transmission Line

(2 $\mathrm{km}$ o $\$ 40 /$ meter)

Insta 11 Concrete Pads

(antenna and transmission line supports)

Dipole Fabrication

(40 required)

Dipole Installation
$\$ 55 \mathrm{~K}$

$30 \mathrm{~K}$

$80 \mathrm{~K}$

$30 \mathrm{~K}$

10K

$80 K$ 
Transmitter Modification: (Per Transmitter) $\begin{array}{lrr}\text { Increase dissipation capability of driver stage } & \$ 11 & \mathrm{~K} \\ \text { Build filament by-passing into tube socket } & 7.5 \mathrm{~K} \\ \text { Purchase output network capacitors and provide } & 16 & \mathrm{~K} \\ \quad \text { cooling for same } & 10 \mathrm{~K} \\ \text { Fabricate network inductor } & 32 \mathrm{~K} \\ \begin{array}{l}\text { Machine surface on boiler and fabricate } \\ \quad \text { coupling capacitor onto boiler surface }\end{array} \\ \begin{array}{l}\text { Complete installation of individual screen } \\ \text { power supply }\end{array}\end{array}$

Total cost for 10 amplifiers

\section{$\$ 96.5 \mathrm{~K}$}

$\$ 965 \mathrm{~K}$

TOTAL cost estimate for $25 \mathrm{MHz}$ capability:

$\$ 1250 \mathrm{~K}$

ニニニニニニ

The cost of a little over $\$ 1.2 M$ is significantly less than the costs associated with the other options presently under consideration. To this cost must be added the cost of operation, manpower and any associated data analyses (\$0.2-0.5 M per year depending on the type of operation and the periods of operation).

Ancillary experiments to assess the impact of high-powered microwaves on the performance of all types of telecommunications systems must also be added to the total cost. However, this would, in all likelihood, be a small cost because much of the supportive requirements (facilities, power, etc.) are readily available in the Platteville area. The overall cost of the ancillary experiments would be lessened by use of existing experimental equipment in place to support on-going HF heater-related work. Any costs for ancillary experiments should be weighed against the flexibility one has in designing and locating such systems. Because of its favorable location, telecommunication systems experiments conducted in support of a Platteville microwave heating simulation can be designed to ensure that the electromagnetic energy that is associated with each telecommunication system is propagated through that region of the ionosphere that is affected by the heater. This feature is certainly a firm requirement of any measurement program undertaken for the express purpose of simulating the operation of the SPS MPTS in order to determine the impact, not just on the ionospheric structure, but on the very real problem of telecommunication system performance. 


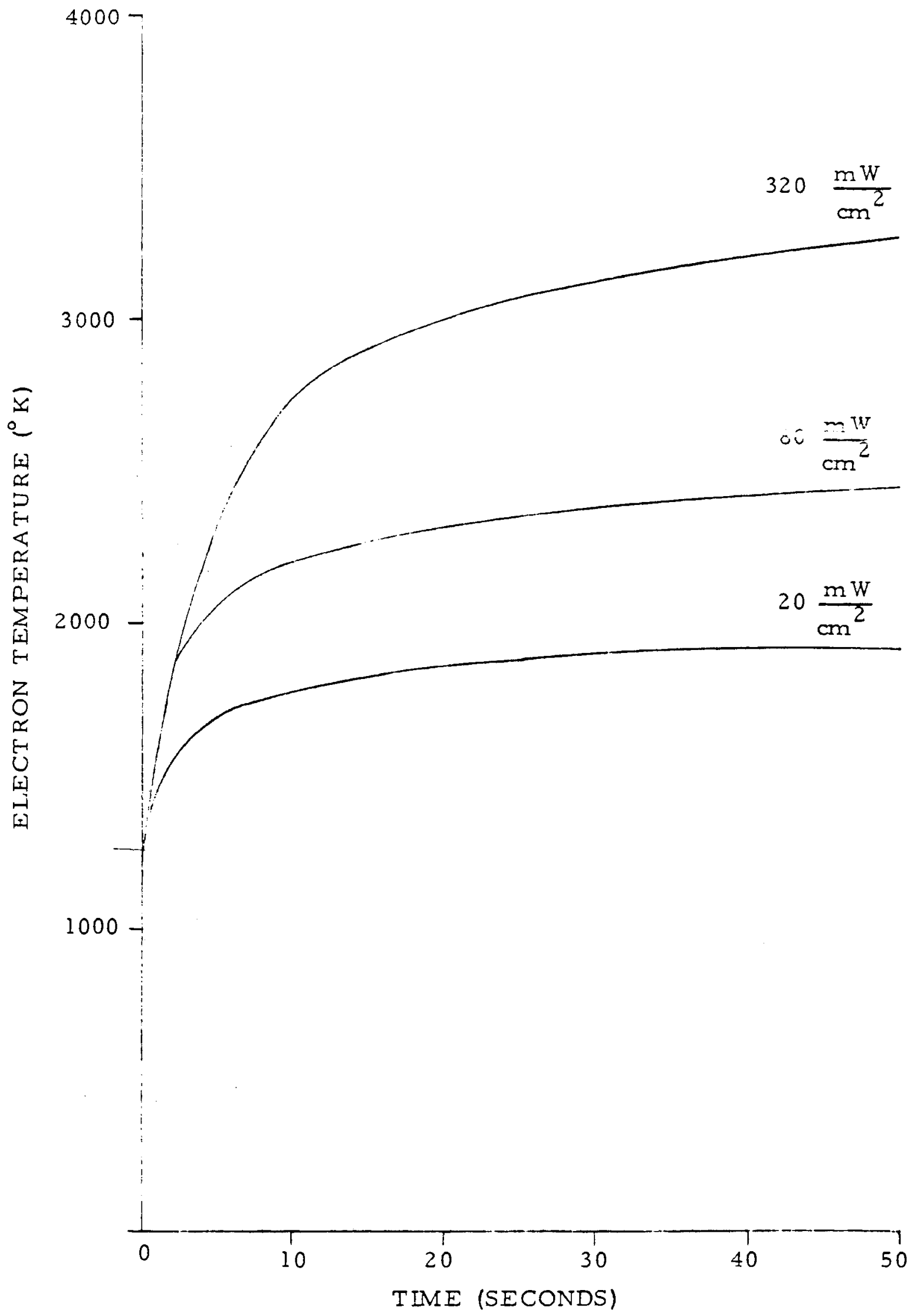

FICURE 4.1. Time Behavior of the Electron Temperature at the Northeast Site at the Point Where the Power Beam is Heating the Peak of the F-Region at $300 \mathrm{~km}$. 


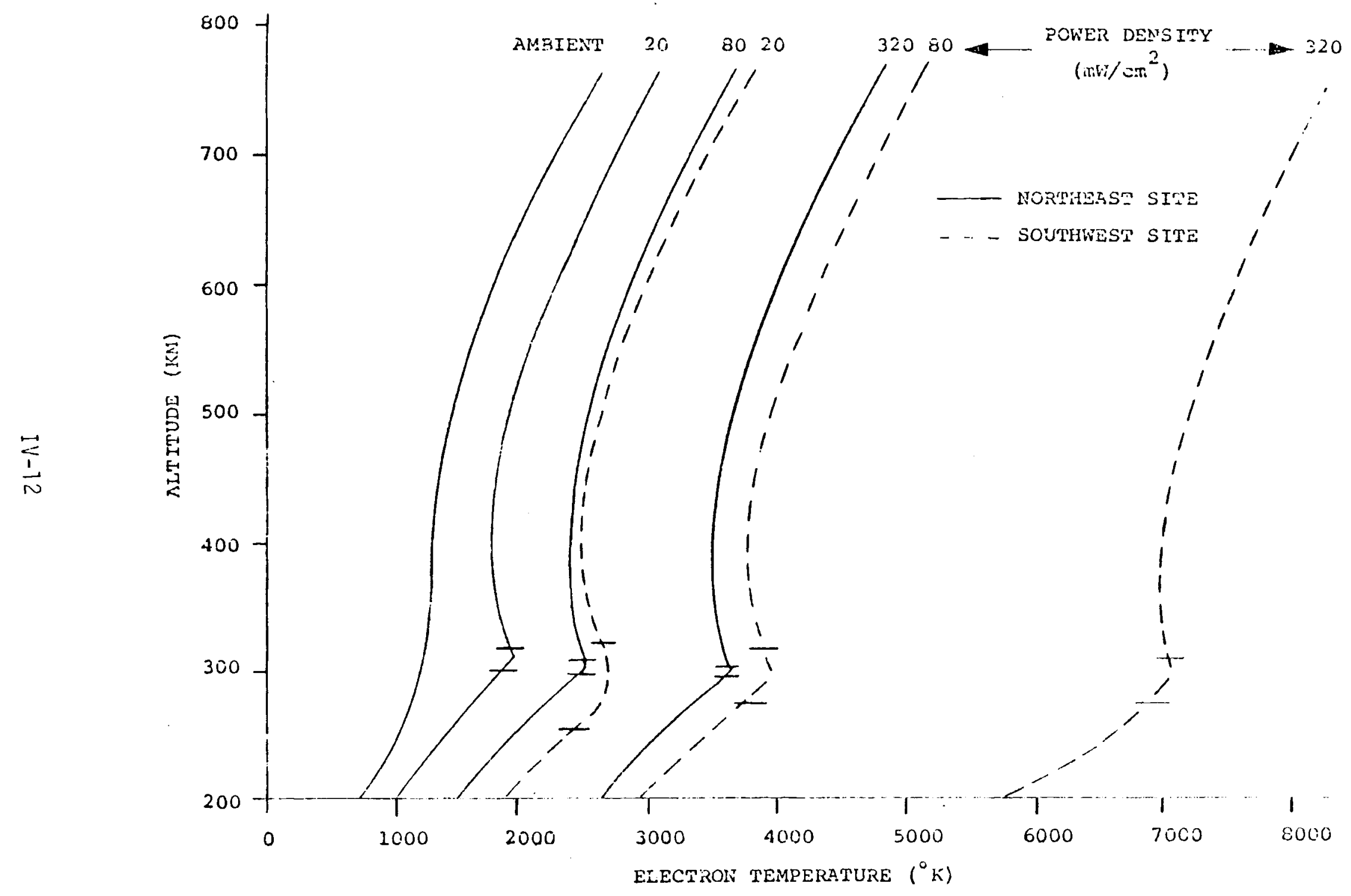

FIGURE 4.2. Steady-state temperature of the nighttime ionosphere as a function of altitude for the power levels and locations specified.

The slash marks on each curve specify limits for the altitude range, centered near $300 \mathrm{~km}$, over which the flux line was heated. 


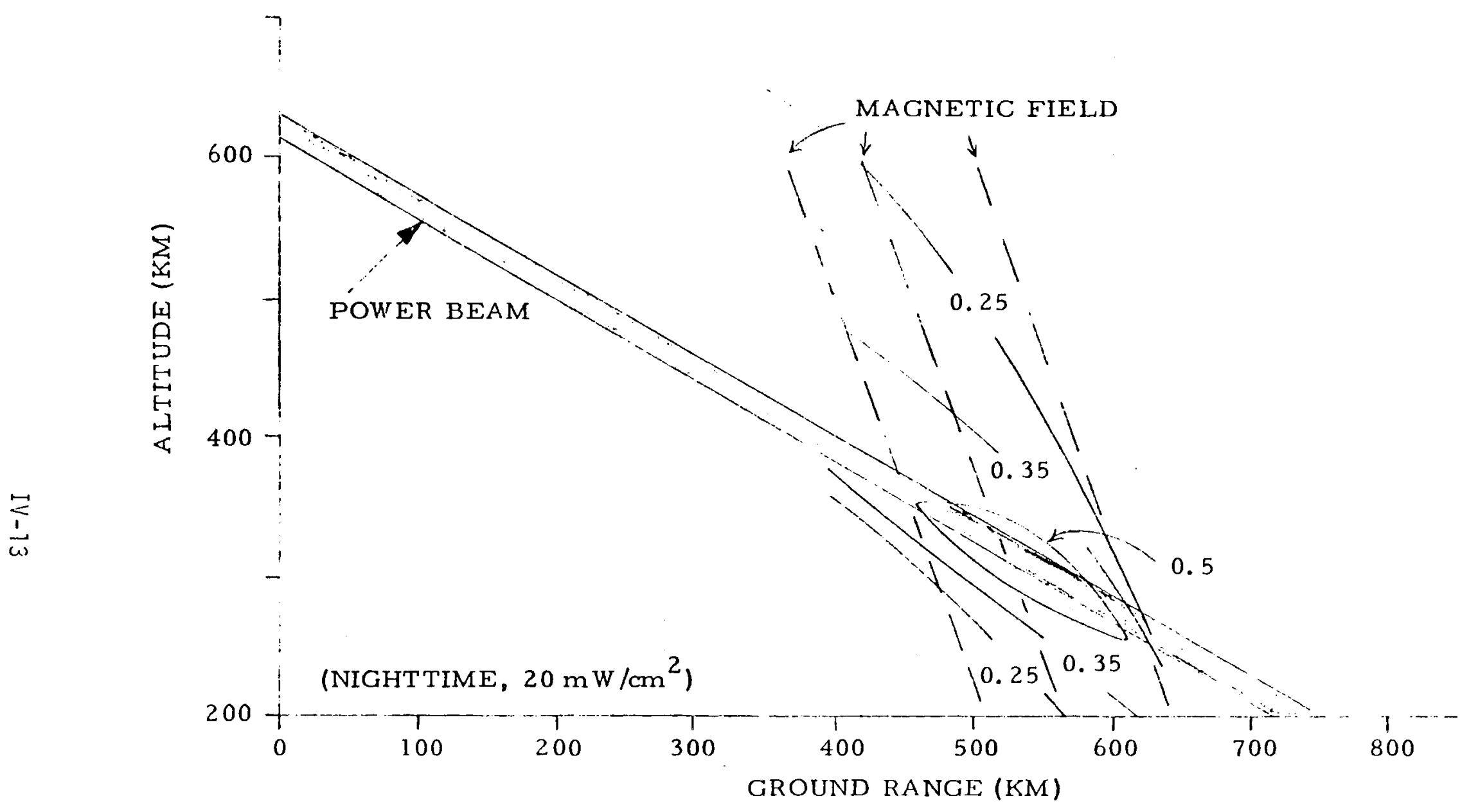

FICURE 4.3. Contours showing the fractional increase in temperature of the electrons in the meridian plane through the axis of the beam, for a nighttime profile at the Northeast site. The curve labeled $20 \mathrm{~mW} / \mathrm{cm}^{2}$ in Figure 4.2 gave absolute values of temperature along a particular magnetic field line which is shown intersecting the power beam at $310 \mathrm{~km}$ altitude in this figure. The largest temperature rise is about 50 percent above ambient and occurs in the vicinity of the beam near the peak of the F-Region where $n v$. 


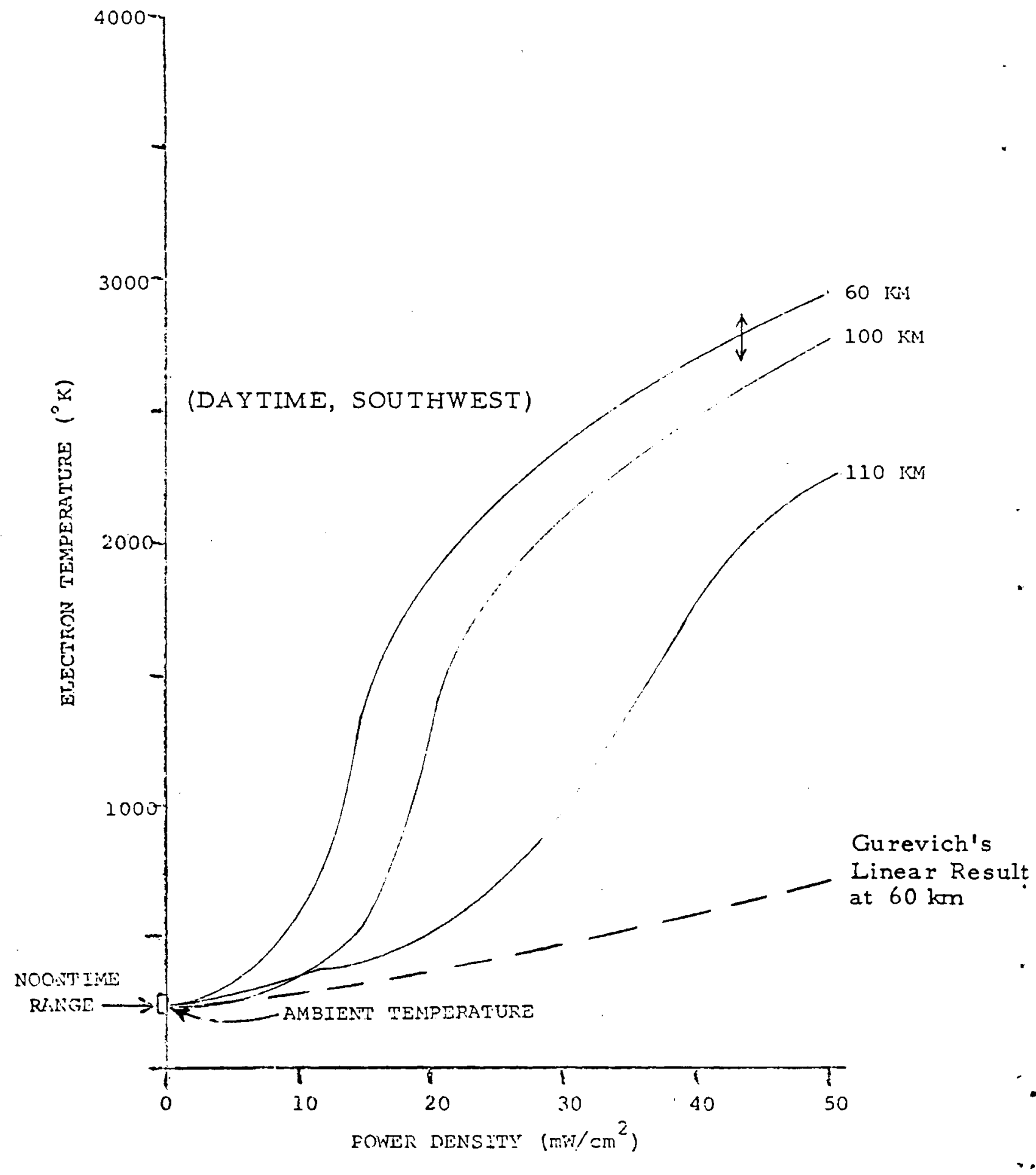

FIGURE 4.4. Electron temperature at 60,100 and $110 \mathrm{~km}$ altitude as a function of incident powe $x$ flux. The dashed straight line is the result which would have been obtained if Gurevich's parameter $G$, which is the fractional energy loss per collision, had been as sumed to be independent of electron temperature, as is correct for weak power fluxes. 


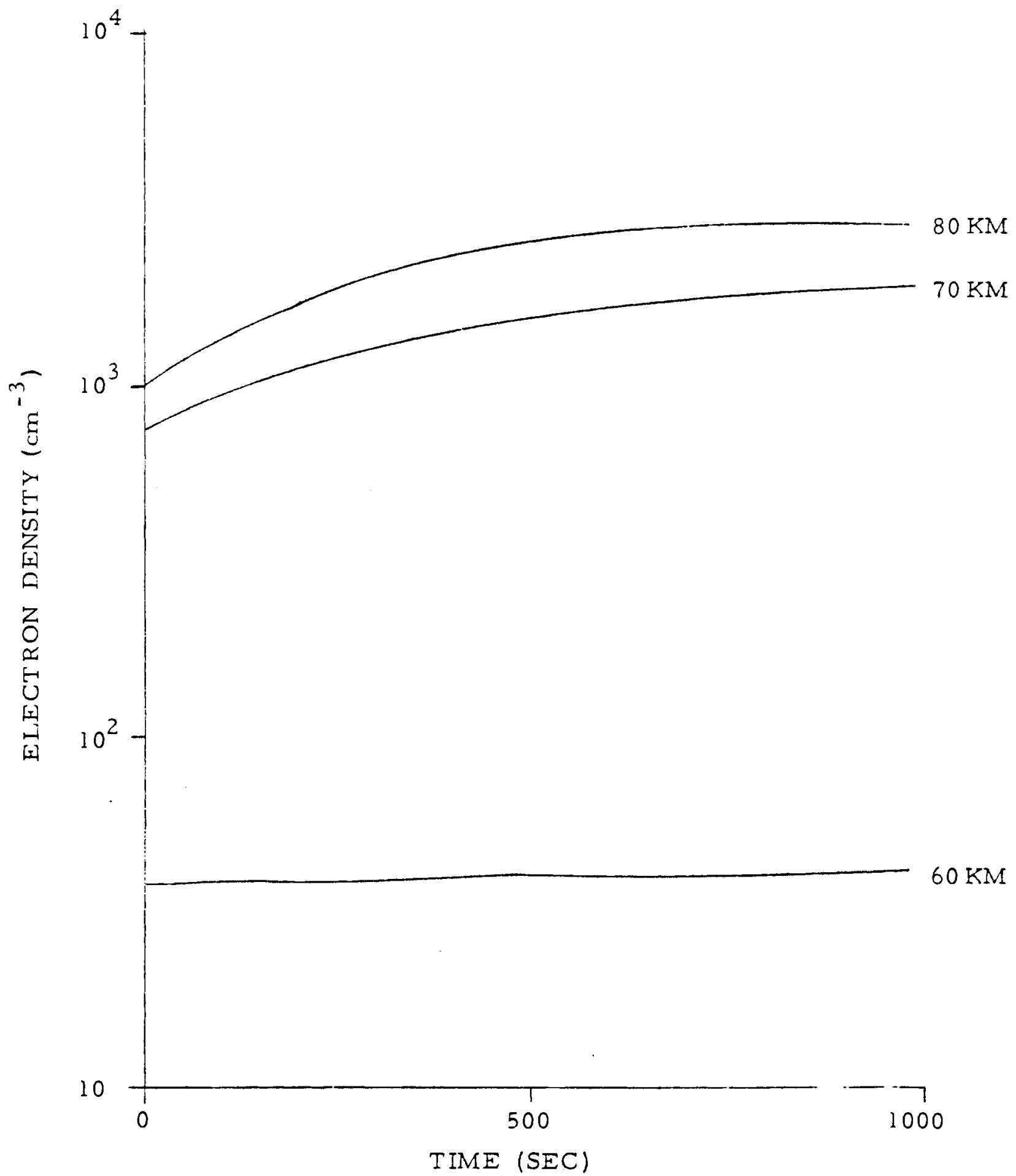

FIGURE 4.5. Electron density as a function of time for 60 , 70 and $80 \mathrm{~km}$ with a $2450 \mathrm{MHz}$ power density of $20 \mathrm{~mW} / \mathrm{cm}^{2}$. 


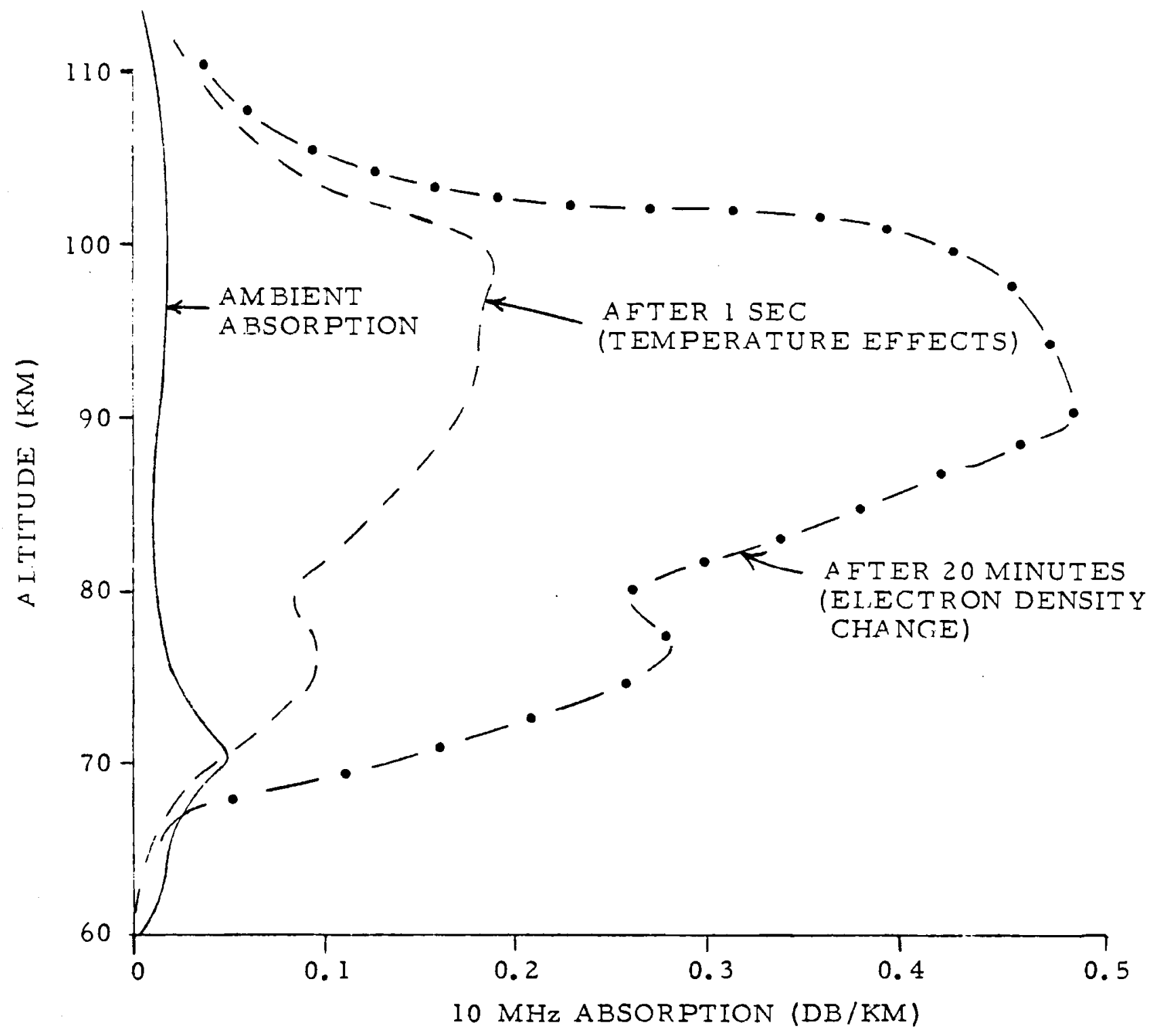

FIGURE 4.6. Absorption coefficient per $\mathrm{km}$ for the power in a $10 \mathrm{MHz}$ ordinary wave passing through the heated portion of the D-Region. NOTE: The incegrated absorption is in excess of $10 \mathrm{~dB}$ for a $10 \mathrm{MHz}$ wave. 
V. Conclusion

The previous sections serve to corroborate the information contained in the report, "Satellite Power Systems RFI-EMI, Preliminary Draft, AD-02-01/82029, Initial Assessment, Electromagnetic Compatibility Aspects of Proposed SPS Microwave Power Transmission System (MPTS) Operations," December 1977. In addition to expanding the information contained in the above-mentioned report, areas in which further work should be undertaken in order to completely assess the impact of SPS operation on telecommunication systems performance, are also described. These areas are:

a. further study on the susceptibility of electronic equipment to SPS emissions (Section II-2);

b. further study on the interference potential of SPS emissions and harmonics to telecommunications systems (Sections II-3 and (I-4);

c. study of the impact of tropospheric attenuation and scattering associated with SPS operation on microwave terrestrial, air/ground and satellite/ground telecommunication systems (Section III-4);

d. further theoretical study on the production of ionospheric irregularities resulting from microwave heating (Section IV-4); and

e. further experimental evidence of the impact of SPS operation on telecommunication systems performance collected in conjunction with a Platteville microwave heating experiment (Section IV-4).

The Institute for Telecommunication Sciences (ITS) is capable of undertaking the tasks to support these areas of further work. The Institute for Telecommunication Sciences is part of the Office of Telecommunications, U. S. Department of Commerce. It is the mission of the ITS to develop the advanced technology needed to assure proper utilization of the radio frequency spectrum to further the National interest.

In addition to appropriately trained personnel, the ITS has available facilities in the field who are equipped to perform telecommunication systems experiments. At the Platteville field-site, the ITS has a facility of proven 
operational reliability and with a relatively modest investment, the current facility can be modified to provide a cost-effective experiment to simulate SPS MPTS effects on radio systems.

Finally, it should be pointed out (as it was in the Battelle report) that operation of the SPS MPTS will require modification of existing international radio regulations. Thus, international politics will come into play. At the national level, the Federal Communications Commission will have to be involved in any decision with regard to an operational SPS. The Communications Act of 1934 (Section 2) gives the FCC jurisdiction over the "transmission of energy by radio." Obviously when the law was passed in 1934, the intent of the Congress was not to include systems such as SPS; nevertheless, the regulatory nature of the Act will have to be addressed. Also worth considering is the United States position with regard to the biological "side effects/hazards" and exposure safety standards for radio and other frequencies associated with telecommunication activities. Within the International Telecommunications Union, steps are being taken to define the electromagnetic environment and other bodies are attempting to define the associated biological hazards. Much more work and information need to be undertaken in this area before any standards could be set. If discussions pertaining to SPS operation were raised in an international forum concerned with telecommunication regulations, it is quite possible that the biological implications of SPS would also surface. The ansiver to these questions may, because of the political realities of the world, be more difficult to obtain than those associated with the technical aspects of SPS operation and implication to telecommunication system performance. 


\section{References}

Bean, B. R. and E. J. Dutton (1968), Radio Meteorology, (Dover Publications, Inc., New York, N. Y.), Chapter 7, pp. 269-308.

Bean B. R., E. J. Dutton, and B. D. Warner (1970), Weather Effects on Radar, Chapter 24 of Radar Handbook, M. I. Skolnik, editor, (McGraw-Hill Book Co., Inc., New York, N. Y.).

Blake, L. V. (1966), Antennas, (John Wiley and Sons, New York, N. Y.), pp. $129-159$.

Battan, L. J. (1959), Radar Meteorology, (University of Chicago Press, Chicago, 11 inois), pp. 32-36.

Battan, L. J. (1971), Radar attenuation by wet ice spheres, J. Applied Meteorology, 10, Apri1, pp. 247-252.

Douglas, R. H. (1964), Hail size distribution, Proc. Eleventh Weather Radar Conference, Boulder, Colo., American Meteorological Soc., pp. 146-149.

Duncan, L. M. and W. E. Gordon (1977), Final Report, "Ionospheric-Microwave Beam Interaction Study," NAS9-15212, DoD No. NA183TA.

Dutton, E. J. (1977), Earth-space Attenuation prediction procedures at 4 to $16 \mathrm{GHz}$, Office of Telecommunications Report OTR 77-123, May (Access No. PB 269-228/AS, NTIS, Springfield, Virginia).

Dutton, E. J., and H. T. Dougherty (1973), Modeling the effects of clouds and rain upon satellite-to-ground system performance, Office of Telecommunications Report 0TR73-5, March (Accession No. COM75-10950/AS, NTIS, Springfield, $V A$ ).

Fraser, R. S. (1959), Scattering Properties of Atmospheric Aerosols, Dept. of Meteorology, U. of California at Los Angeles (UCLA), (Access No. 233-288, NTIS, Springfield, Virginia).

Gary, M., R. McAffee, Jr., and C. L. Wolf (1972), Glossary of Geology, (American Geological Institute, Washington, D. C.), p. 627.

Gordon, W. E. and H. C. Carlson, Jr. (1974), Arecibo Heating Experiments, Radio Sci., 9, pp. 1041-1048.

Holway, L. H., Jr., A. H. Katz, and G. Meltz (1978), Ionospheric Effects of a High Power Space-Borne Microwave Beam, Proc. of 1978 Symposium on the Effect of the Ionosphere on Space and Terrestrial Systems, Jan. 24-26, 1978. 
Hubbard, R. W., J. A. Hu11, P. L. Rice, and P. I. Wells (1973), An experimental study of the temporal statistics of radio signals scattered by rain, Office of Telecommunications Report OTR73-15, June (Accession No. N7412845, NTIS, Springfield, VA).

ITU (1976), Radio Regulations, Vol. 1, Article 7, Paragraph 470ND, Special rules relating to particular services, Published by the General Secretariat of the International Telecommunications Union (ITU), Geneva.

Kerr, D. E. (1951), Propagation of Short Radio Waves, (McGraw-Hil1 Book Co., Inc., New York, N. Y.), pp. 451-453.

Meltz, G. and R. E. LeLevier (1970), Heating of the F-region by Deviative Absorption of Radio Waves, J. Geophys. Res., 75, pp. 6406-6416.

Perkins, F. W. and R. G. Roble (1978), Ionospheric Heating by Radio Waves:

Predictions for Arecibo and the Satellite Power Station, J. Geophys. Res., 83, In Press.

Radio Science (1974), Special Issue: Ionospheric Modification by High Power Transmitters, November 1974.

Raytheon (1977), Space-Based Solar Power Conversion and Delivery Systems Study, II Microwave Power Transmission System, NASA MSFC, March 1977. Utlaut, W. F. (1975), Ionospheric Modification Induced by High-Powered HF Transmitters: A Potential for Extended Range VHF-UHF Communications and Plasma Physics Research, Proc. 63, pp. 1022-1043.

Zuffery, C. H. (1972), A Study of Rain Effects on Electromagnetic Waves in the 1-600 GHz Range, U. of Colorado, Dept. of Elect. Eng. Thesis, Boulder, Colo., February. 
PNL-2616

UC-97a

\section{DISTRIBUTION}

No. of

Copies

OFFSITE

1 DOE Chicago Patent Group US Department of Energy Argonne, IL 60439

A. A. Churm

27 DOE Technical Information Center

7 Argonne National Laboratory $400 \mathrm{~N}$. Capitol Street NW Washington, DC 20001

CA Sandahl

9700 South Cass Avenue Argonne, IL 60439

$T$ Wolsko (6)

16 Department of Energy

Division of Biomedical and Environmental Research Washington, DC 20545

$T$ Gross (2)

Solar, Geothermal, Electrical and Storage Systems 20 Massachusetts Avenue NW Washington, DC 20545 EH Will is (1)

Division of Solar Technology 600 East Street NW Washington, DC 20545

FA Koomanoff (5) JF Madewe 11

HH Marvin

Division of Technology Overview Rt. 270

Germantown, MD 20545

$\mathrm{R}$ Blaunstein (6)
No. of

OFFSITE

3 Institute for Telecommunication

Sciences

325 Broadway

Boulder, CO 80302

CM Rush

1 Jet Propulsion Laboratory 4800 Oak Grove Drive Pasadena, CA 91103 $R$ Dickinson

3 Los Alamos Scientific Laboratory Box 1663 Los Alamos, NM 87545

$\mathrm{J}$ Hopkins

43 National Aeronautics and Space Administration NASA Headquarters Washington, DC 20546
$H$ Calahan (2)
$R$ LaRock (1)
$S$ Manson (2)

Johnson Space Center

Houston, TX 77058

$L$ Bell (3)

C Covington (4)

$H$ Davis (1)

0 Garriott (6)

$\mathrm{J}$ Loftus (1)

$R$ Piland (2)

Marshall Space Flight Center Huntsville, AL 35812

$K$ Fikes (15)

C Guttman (5)

J Murphy (1) 
No. of

Copies

OFFSITE

$4 \quad$ Planning Research Corporation

7600 01d Springhouse Road

McLean, VA 22101

C Bain

2 Solar Energy Research Institute

1536 Cole Boulevard

Golden, co 80401

$P$ Rappaport

\section{ONSITE}

1 DOE, Richland Operations Office Federal Building

Richland, WA 99352

HE Ransom

6 Battelle-Northwest

P.0. Box 999

Richland, WA 99352

WJ Bair

KC Davis

$K$ Drumheller

PA Ekstrom

CL Simpson

RA Stokes

Technical Information Files

(5)

Technical Publications (4) 